\title{
LA ARBORICULTURA: QUEHACER DEL ARBORISTA
}

\author{
Alicia Chacalo ${ }^{1}$
}

Daniel Zansi, Fundador del capítulo Italiano de la ISA y quién fue Presidente hace algunos años del mismo capítulo, decía que en Italia dedicarse al cuidado de los árboles era similar a trabajar para el servicio de la limpieza. Todos los que se quedaban sin trabajo, podían elegir la arboricultura como remedio.

En México algunos de nuestros primeros arboristas, cuentan hoy que en sus inicios empíricos, cuando aun no eran arboristas profesionales, comenzaron desmochando árboles por falta de conocimientos apropiados.

Otros presumen haber plantado ya miles de árboles a lo largo y ancho del país pero ¿que es en realidad la arboricultura? ¿Cual es la importancia del trabajo de un arborista? ¿Cuántos miles de árboles tenemos que plantar para decir que somos arboristas?

La arboricultura es la disciplina dedicada al cuidado de los árboles en el ambiente construido. Se diferencía de las ciencias forestales o de la dasonomía en un aspecto fundamental: el cuidado y atención personalizada que se le da a cada árbol. Si, aunque parezca inaudito, se trata de brindar atención a árbol por árbol.

Mientras que la dasonomía atiende al bosque, la arboricultura o el arborista se encargan del individuo; de los árboles de las calles, de las carreteras, los de los parques urbanos, de los árboles majestuosos. De todos los árboles que se plantan en el hábitat humano y que están afectados por este, aunque estén a decenas de metros de distancia del poblado más cercano.

Hace algunos años, la arboricultura se consideraba en México una disciplina técnica. "Plantar arbolitos lo puede hacer cualquiera", se pensaba con frecuencia en diversos ámbitos académicos. La cruda realidad observada algunos años posteriores a las plantaciones masivas y carentes de criterios apropiados realizadas al principio de la década de los 80 por diversas instancias gubernamentales, han mostrado ahora que, si bien cualquiera puede plantar un árbol, no cualquiera puede elegir la mejor especie para cada sitio, no todos pueden brindar a los árboles el mantenimiento necesario durante su crecimiento, ni hacer que ese árbol plantado sea un verdadero patrimonio en el paisaje en la edad adulta.

\footnotetext{
${ }^{1}$ Profesora Dra. de la Universidad Autónoma Metropolitana - Azcapotzalco Editora de ArbóreA México D. F., ach@correo.azc.uam.mx
} 
Muchos de los millones de árboles plantados en los 80's, morían cada año y debían ser reemplazados por otro árbol. Y muchos millones de sobrevivientes, tienen hoy severos problemas de interferencia con el cableado eléctrico y la infraestructura urbana o se han ido eliminando paulatinamente por todos los problemas que han ocasionado, tal como ha ocurrido con el eucalipto.

Sin duda alguna esa es una de las principales tareas de un arborista.

En la ISA, Sociedad Internacional de Arboricultura (por sus siglas en Inglés), la profesión se subdivide en varios sectores.

El Comercial que brinda atención al cliente para la plantación, el mantenimiento o el derribo del arbolado.

El Municipal es el responsable del cuidado de los árboles en las Delegaciones o Municipios.

El de Educación e investigación, sector que se dedica a apoyar a través de conocimientos científicos los fundamentos de esta ciencia.

Y el de Servicios de Cableado brinda el cuidado especial que requieren los árboles plantados bajo líneas de conducción. Para proceder, eneste sector, se requiere de una capacitación especializada para poder atender a los árboles cercanos a los cables de electricidad, principalmente en la poda.

Todas estas son tareas de un arborista y no importa si has plantado millones de árboles o has plantado sólo uno, lo que si es importante es que se haya hecho con los principios y fundamentos de cómo y por que hacerlo y que los resultados muestren por sí solos que, la diferencia entre el buen conocedor y el trabajador empírico, se releja en la calidad del ambiente lograda. 